\title{
Immunization with T Cell Receptor V $\beta$ Chain Peptides Deletes Pathogenic T Cells and Prevents the Induction of Collagen-induced Arthritis in Mice
}

\author{
Tariq M. Haqqi, ${ }^{\star \ddagger \S}$ Xue-Mei Qu, ${ }^{\star}$ Donald Anthony, ${ }^{\star}$ Jing Ma, ${ }^{\ddagger}$ and Man-Sun Sy ${ }^{\ddagger \S}$ \\ Departments of $*$ Medicine, ${ }^{*}$ Pathology, and ${ }^{\S}$ Dermatology, Biomedical Research Building, Case Western Reserve University, \\ Cleveland, $\mathrm{OH} 44106-4946$
}

\begin{abstract}
Collagen-induced arthritis (CIA) in susceptible strains of mice is an animal model of $T$ cell-mediated inflammatory polyarthritis. Analysis of $\mathrm{T}$ cell receptor (TCR) $\mathrm{V} \beta$ gene usage in cells isolated from arthritic joints of $\mathrm{BUB} / \mathrm{BnJ}$ (BUB) mice $\left(H-2^{q}\right.$, TCR V $\left.\beta^{a}\right)$ showed that TCR V $\beta$ chain gene usage was limited to TCR V 33 and $V \beta 10$ gene families. All of the BUB mice immunized with a mixture of TCR V $\beta 3$ and TCR V $\beta 10$ peptides, but not with control TCR V $\beta 14$ peptide, were refractory to the induction of CIA. Immunization with TCR V 33 and $V \beta 10$ peptides completely blocked the development of clinical and subclinical inflammation, formation of pannus and synovial hyperplasia, and the erosion of cartilage and bone. Further studies revealed that preimmunization of BUB mice with $V \beta 10$ peptide alone was sufficient to render the mice resistant to CIA. Analysis of TCR V $\beta$ chain gene expression in lymph node cells from arthritic and arthritis-protected mice showed the expression of TCR V $\beta 10$ subfamily in all of the arthritic mice, but not in arthritis-protected mice. Immunization with TCR V $\beta$ peptides did not diminish the humoral responses to chicken type-II collagen and also elicited significant levels of anti-V $\beta 3$ and anti-V $\beta 10$ peptide antibodies. Antibodies cross-reactive with mouse chicken type-II collagen were detected in both the arthritic and arthritis-protected mice. Adoptive transfer of serum from arthritis-protected BUB mice significantly delayed the onset $(P<0.005)$ of arthritis in recipient BUB mice. In contrast, mice injected with serum from arthritic mice had early onset of arthritis. These results demonstrate that immunization of BUB mice with TCR V $\beta$ chain peptides elicited antibodies reactive with the self-TCR and prevented the induction of collageninduced arthritis by eliminating or downregulating pathogenic $\mathrm{T}$ cells and consequently blocking the development of humoral immune response. These findings may have clinical applications in treating human autoimmune diseases characterized by common TCR gene usage. (J. Clin. Invest. 1996. 97:2849-2858.) Key words: vaccination • polymerase chain reaction $\bullet$ inflammation $\bullet$ animal model $\bullet T$ cell receptor
\end{abstract}

\footnotetext{
Address correspondence to Tariq M. Haqqi, Division of Rheumatic Diseases, Department of Medicine, Biomedical Research Building, Case Western Reserve University, 10900 Euclid Avenue, Cleveland, OH 44106-4946. Phone: 216-368-1374; FAX: 216-368-1332; E-mail: txh5@cwru.edu

Received for publication 17 August 1995 and accepted in revised form 22 March 1996.
}

J. Clin. Invest.

(C) The American Society for Clinical Investigation, Inc. 0021-9738/96/06/2849/10 \$2.00

Volume 97, Number 12, June 1996, 2849-2858

\section{Introduction}

Collagen-induced arthritis (CIA) ${ }^{1}$ in mice is an animal model of inflammatory polyarthritis with clinical and pathological features similar to rheumatoid arthritis. Arthritis develops in susceptible $\mathrm{H}-2^{\mathrm{q}}$ or $\mathrm{H}-2^{\mathrm{r}}$ strains of mice after immunization with native type-II collagen (CII), a major component of the articular cartilage, in CFA $(1,2)$. The immunogenic and arthritogenic epitopes in the CII molecule have been localized to a 279-amino acid-long fragment cleaved by cyanogen bromide. The ensuing arthritis is characterized by inflammation within the joint and is associated with synovial hyperplasia, infiltration of the subsynovial tissue with inflammatory cells, and erosion of cartilage and bone. Both humoral and cellular immunity against CII can be detected in arthritic mice and are necessary for the onset and severity of the disease (3). In CIA, although anti-CII antibodies contribute to arthritogenic process, severe and chronic arthritis is primarily mediated by CIIreactive $\mathrm{T}$ cells. The critical role of cellular immunity in CIA was established when $\mathrm{CD}^{+} \mathrm{T}$ cell lines and clones, specific for a fragment of the collagen molecule, were shown to be pathogenic or protective when inoculated into syngeneic-naive recipients $(3,4)$. Analysis of T cell receptor (TCR) V $\beta$ gene expression in cells obtained from arthritic joints of B10.Q mice $\left(\mathrm{H}-2^{\mathrm{q}}, \mathrm{TCR} \mathrm{V} \beta^{\mathrm{b}}\right)$ or lymph node (LN) cells from CII-immunized DBA/1 mice showed limited heterogeneity in TCR V $\beta$ gene usage $(5,6)$. The phenomenon of restricted TCR V $\beta$ gene usage is not unique to CIA as similar findings have been reported in the experimental allergic encephalomyelitis (EAE) model. In the EAE model, TCR V $\beta 8.2$ was found to be preferentially used by the encephalitogenic T cells $(7,8)$. Interestingly, TCR V $\beta 8.2$ was also found to be used by the jointinfiltrating T cells in mice with CIA (5). Subsequent studies, in rats and mice, demonstrated that immunization of susceptible animals with TCR V $\beta 8.2$ peptides induced protection against $\mathrm{EAE}$, and the protection was mediated by both the B cells and the idiotypic-specific regulatory T cells $(9,10)$.

In a previous report, we showed that mice of an inbred strain, BUB/BnJ (BUB) $\left(\mathrm{H}-2^{\mathrm{q}}\right)$, with genomic deletion of TCR $\mathrm{V} \beta 5,8,9$, and 11-13 gene families are highly susceptible to the development of CIA with the incidence and severity of arthritis being similar to that in DBA/1 mice (11). We have also demonstrated that $\mathrm{T}$ cells in the arthritic joints of BUB mice are predominantly of the Th- 1 type and show a restricted TCR $\mathrm{V} \beta$ chain gene usage limited to TCR V $\beta 3$ and 10 gene families (12). Data obtained by molecular cloning and sequence analysis of the amplified TCR V $\beta$ fragments from arthritic joints of BUB mice provided evidence of antigen-driven clonal expan-

1. Abbreviations used in this paper: $\mathrm{BUB}, \mathrm{BUB} / \mathrm{BnJ}$; CIA, collageninduced arthritis; CII, chicken type-II collagen; EAE, experimental allergic encephalomyelitis; IFA, incomplete Freund's adjuvant; LN, lymph nodes; TCR, T cell receptor. 
sion of some of the T cell clones (12). In the present report, we demonstrate that preimmunization of BUB mice with a mixture of TCR V 33 and TCR V $\beta 10$ synthetic peptides, or with TCR V $\beta 10$ synthetic peptide alone, induced protective immunity against the induction of CIA. Similar protection against CIA was not induced by immunization with TCR V $\beta 14$ peptide. Results presented in this communication show that: $(a)$ immunization of BUB mice with a mixture of TCR V 3 and $\mathrm{V} \beta 10$ peptides prevented the induction of CIA; $(b)$ no influence on humoral immune response to chicken type-II collagen or to the immunizing TCR V $\beta$ peptides was observed; $(c)$ immunization with TCR V $\beta$ peptides influenced the production of antibodies cross-reactive with mouse type-II collagen; and (d) protection against CIA can be transferred by immunizing mice with serum from arthritis-protected mice. Our data also show that immunization with TCR V $\beta 3$ and V $\beta 10$ peptides did not alter the repertoire of T cells expressing TCR V $\beta 2,4$, $6,13,14$, or $17^{\mathrm{a}}$ subfamilies, indicating the specificity of the immune response. These results thus provide evidence of the elicitation of antibodies reactive with the self-TCR in BUB mice immunized with TCR V $\beta$ peptides, and the involvement of humoral immune response in inducing protective immunity against CIA. Our studies demonstrate that approaches based on targeting the TCR V $\beta$ region of oligoclonal T cells could be an effective way of treating autoimmune diseases in general and arthritis in particular.

\section{Methods}

Mice. 6-8 wk-old, male, BUB/BnJ mice (H-2q, TCR V $\beta^{\text {a }}$ ) were purchased from The Jackson Laboratories (Bar Harbor, ME). Mice were maintained at the Animal Care Facilities of the School of Medicine (Case Western Reserve University, Cleveland, OH). All animal experimentation work and handling of animals was carried out in accordance with National Institutes of Health guidelines and with the approval of Institutional Animal Care and Use Committee.

Synthesis of TCR V $\beta$ peptides. We identified regions in the TCR $\mathrm{V} \beta 3$ and $\mathrm{V} \beta 10$ molecules which were predicted to be immunogenic $(13,14)$. Synthetic peptides representing amino acid residues 13-29 in the TCR V 3 molecule (KGQGQKAKMRCIPEKGH) and amino acid residues 25-46 in the TCR V $\beta 10$ molecule (QTLDHNTMYWYKQDSKKLLKIM) were synthesized by Tana Laboratories (Houston, TX). A control peptide, representing amino acid residues 39-56 (ATGGTLQQLFYSITVGQV) and corresponding to murine TCR V $\beta 14$ gene, was synthesized by Chiron Mimotopes Peptide Systems (San Diego, CA). In all cases, amino acid sequence of the peptides is written using the single letter amino acid code.

Chicken type-II collagen. The CII used in these studies was provided by the Biotech Holdings (Hudson, $\mathrm{OH}$ ) and was stored lyophilized in a freezer before use. CII was dissolved in $0.05 \mathrm{M}$ acetic acid $(2 \mathrm{mg} / \mathrm{ml})$ by gentle rotation at $4^{\circ} \mathrm{C}$ overnight and then emulsified in CFA (1:1) for immunizations as described below.

Immunizations. Mice were divided into three groups designated A, B, and C. 10 mice in group A were first immunized with a $1 \mathrm{mg} / \mathrm{ml}$ solution (in PBS) of TCR V 33 and V $\beta 10$ peptides emulsified with an equal volume of CFA (GIBCO-BRL, Gaithersburg, MD) and $100 \mu \mathrm{l}$ of the emulsified mixture was injected intradermally in the tail. $10 \mathrm{~d}$ later, these mice were immunized with chicken type-II collagen for the induction of arthritis as previously described (15). This experiment was repeated once more with a new batch of 10 mice and this group was designated as group A1.

Six mice in group B were first immunized with a $1 \mathrm{mg} / \mathrm{ml}$ solution (in PBS) of TCR V $\beta 14$ peptide emulsified in CFA and $100 \mu l$ was injected intradermally in the tail. $10 \mathrm{~d}$ later, these mice were immunized with chicken type-II collagen for the induction of arthritis as de- scribed above. Eight mice in group $\mathrm{C}$ were immunized with $100 \mu \mathrm{l}$ of a mixture of PBS + CFA and $10 \mathrm{~d}$ later were immunized with chicken type-II collagen for the induction of arthritis as above.

In all the groups, mice were monitored for the development of clinical symptoms of arthritis up to $40 \mathrm{~d}$ after immunization with chicken type-II collagen emulsified in CFA (16). The day of onset of arthritis was considered to be the day when erythema and/or swelling was first observed in one or more limbs and was counted from the day when mice were first immunized with chicken type-II collagen. Severity of arthritis on the day of onset was determined by evaluating fore and hind paws for swelling and redness and was scored on a subjective scale as previously described $(15,16)$.

Histological analysis of the joints. Histological analysis of the joints $(n=4)$ was carried out using the facilities of the Histology and Immunochemistry Core of the Northeast Ohio Multipurpose Arthritis Centre (NEOMAC). The first limb to show clinical arthritis (usually the hind paw) was removed from four dead mice in the affected groups, formalin fixed, and processed for histological analysis as previously described (16). In all cases, clinical severity of arthritis was of identical duration. Mice from groups A and A1 were killed $40 \mathrm{~d}$ after immunization with chicken type-II collagen and the hind paws were also formalin fixed and processed as for arthritic mice. In this way, comparisons were made between the arthritic and nonarthritic joints. Trichrome-stained sections were examined under a microscope and photographed using the photomicrography system (Nikon Inc., Instrument Group, Melville, NY).

Immunization of BUB mice with either TCR V 3 or TCR V $\beta 10$ peptide. We also studied if preimmunization with only one TCR V $\beta$ peptide could also induce protective immunity against CIA. Two groups of mice were immunized with $500 \mu \mathrm{g}$ of either TCR V $\beta 3$ or TCR V $\beta 10$ peptide in CFA before immunization with CII. $10 \mathrm{~d}$ later, these mice were immunized with $100 \mu \mathrm{g}$ of chicken type-II collagen for the induction of arthritis (15). Mice in these groups were also monitored for the development of clinical symptoms of arthritis up to $40 \mathrm{~d}$ after immunization with chicken type-II collagen. Day of onset and severity of arthritis was determined as described above.

Determination of serum antibody titers. Serum titers of anti-type-II collagen antibodies in BUB mice were determined by an ELISA method as previously described (16). The values obtained were represented in arbitrary OD units.

Serum samples were also analyzed for the presence of mouse anti-V $\beta 3$ and mouse anti-V $\beta 10$ peptide antibodies by adapting the previously described ELISA method (16). Briefly, each well of a microtiter plate was coated overnight at $4^{\circ} \mathrm{C}$ with $100 \mu$ of TCR V 33 or TCR V $\beta 10$ peptide $(10 \mu \mathrm{g} / \mathrm{ml})$ and then blocked by incubation with PBS containing $1 \%$ fetal calf serum. Plates were then washed thoroughly and a 100- $\mu$ l aliquot of each serum sample, diluted in PBS, was added to the wells and the plates were incubated at $37^{\circ} \mathrm{C}$ for $2 \mathrm{~h}$. The plates were again washed and incubated for $2 \mathrm{~h}$ with alkalinephosphatase-conjugated goat anti-mouse IgG (PharMingen, San Diego, CA). The plates were then thoroughly washed and the phosphatase substrate (Sigma Chemical Co., St. Louis, MO) was added and the color was allowed to develop. Absorbance was determined on an ELISA reader at $410 \mathrm{~nm}$ and the values were represented in arbitrary OD units.

Immunization of BUB mice with serum from arthritic and arthritis-protected mice. Serum from arthritic BUB mice (immunized with TCR V $\beta 14$ peptide) and from arthritis-protected BUB mice (immunized with a mixture of TCR V $\beta 3$ and V $\beta 10$ peptides) was obtained by tail bleeding followed by centrifugation. Serum was stored frozen before use. Eight mice were each injected i.v. with $100 \mu \mathrm{l}$ of serum mixed with $200 \mu \mathrm{l}$ of sterile PBS twice a week. This treatment was started on the day of immunization of BUB mice with chicken type-II collagen (day 1) for the induction of arthritis and continued up to 1 wk after booster immunization (CII + incomplete Freund's adjuvant, IFA). Four mice in the control group received equivalent amounts of serum plus PBS from arthritic BUB mice. In the third group, four mice were injected with normal BUB mouse serum plus 
PBS. Incidence and severity of arthritis, in each group, was determined as described above. This regimen of multiple infusions of diluted serum was chosen. As in preliminary studies, we found that single injections of even $200 \mu \mathrm{l}$ of serum had no effect on the incidence or severity of arthritis. Mice in this set of experiments were observed for the development of clinical symptoms of arthritis up to day 60 after primary immunization.

Determination of TCR V $\beta$ gene expression by PCR. We determined the TCR V $\beta$ chain gene expression in the draining lymph nodes cells and spleen cells of some of the mice from each group by PCR-assisted amplification of TCR V $\beta$ transcripts essentially as previously described $(5,11,12)$. Briefly, $1 \mu \mathrm{g}$ of total cellular RNA was reverse transcribed into cDNA using random primers (cDNA Cycle Kit; Invitrogen Corp., San Diego, CA). The cDNA was digested with RNase-H (GIBCO BRL), heated to $80^{\circ} \mathrm{C}$ for $10 \mathrm{~min}$, and then purified using Chromaspin-400 columns (Clontech, Palo Alto, CA) and used in the PCR-assisted amplification of TCR V $\beta$ transcripts. Specificity of the amplified products was determined by: $(a)$ size of the amplified fragment; and $(b)$ hybridization with a $\mathrm{C} \beta$ oligonucleotide probe (5'-AGAACCCCCTGATGATAGGAT- $\left.3^{\prime}\right)$ with sequence internal to the sequence of the $C \beta$ primer used for PCR amplification as previously described (12). Relative level of expression of TCR V $\beta$ 3 - and TCR V $\beta$ 10-chain genes in LN and spleen cells of arthritic and arthritis-protected mice was derived from these autoradiograms using PC-based scanning and analysis (Gelpro-Analyzer, Media Cybernetics, Inc., Silver Springs, MD) essentially as previously described (17) except that abundance of the V $\beta$ transcripts was calculated relative to the radiographic intensity of the constant region $(C \beta)$ fragment.

Flowcytometric analysis. Spleen and LN cells $\left(2 \times 10^{5}\right)$ were washed with sterile PBS in 5\% normal mouse serum and $0.1 \% \mathrm{NaN}_{3}$ and incubated on ice for 30 min with phycoerythin-labeled mAb 145-2C11

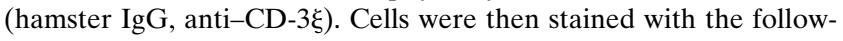
ing FITC-labeled antibodies specific for murine V $\beta$ TCR: B 20.6 (rat IgG, anti-V $\beta-2$ ), KT4 (rat IgG, anti-V $\beta-4$ ), RR4-7 (rat IgG, anti-V $\beta-6$ ), MR12-3 (mouse IgG, anti-V $\beta-13$ ), 14-2 (rat IgG, anti-V $\beta-14$ ), and $\mathrm{KJ}-23$ (mouse IgG, anti-V $\beta-17 \mathrm{a}$ ). All of the antibodies were purchased from PharMingen. Cell staining was determined using FACSCAN ${ }^{\circledR}$ and gating on lymphocytes.

\section{Results}

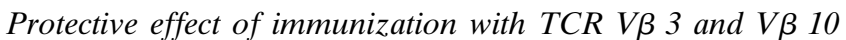
peptides on CIA. The development and progression of arthritis in BUB mice that results after immunization with chicken type-II collagen has been previously reported (11). A high percentage of BUB mice developed arthritis with rapid disease progression when they were immunized with CII in CFA and then challenged 3 wk later with CII + IFA. Analysis of TCR $\mathrm{V} \beta$ gene expression in lymphocytes isolated from arthritic joints revealed a restricted heterogeneity in their TCR V $\beta$ gene usage. The majority of the infiltrating $\mathrm{T}$ cells expressed either TCR V 33 or V $\beta 10$ gene family (12). Since V $\beta 3$ - and $\mathrm{V} \beta$ 10-bearing $\mathrm{T}$ cells may be involved in the pathogenesis of arthritis, we investigated whether immunization of BUB mice with TCR V $\beta 3$ and TCR V $\beta 10$ peptides can modulate the development of arthritis. The results of a representative experiment, using a mixture of TCR V $\beta 3$ and V $\beta 10$ peptides, are shown in Table I. Mice in group A were immunized with a mixture of TCR V $\beta 3$ and V $\beta 10$ peptides $10 \mathrm{~d}$ before immunization with CII + CFA. These mice were then challenged with CII in IFA 3 wk later (a protocol which results in a very high incidence of arthritis, references 11,12). The development of arthritis was monitored for up to $40 \mathrm{~d}$ after initial immunization with CII + CFA. None of the mice preimmunized with TCR V 3 and V $\beta 10$ peptides developed any clinical symp- toms of arthritis. This experiment was repeated once again with 10 more mice being treated identically (group A1). None of the mice in the second group developed any clinical symptoms of arthritis up to $40 \mathrm{~d}$ after immunization with CII + CFA either (Table I). Mice in group B were immunized with the control TCR V $\beta 14$ peptide $10 \mathrm{~d}$ before immunization with $\mathrm{CII}$ in CFA. These mice were then treated exactly as mice in group A and group A1. A high incidence and severity of arthritis occurred in mice in this group $(5 / 6 ; 83 \%)$. Mice in this group (group B) developed clinical arthritis (arthritis score 2.0 on the day of onset) within $40 \mathrm{~d}$ of immunization with CII, with clinical arthritis becoming evident around day 30 (Table I). Mice in group $\mathrm{C}$ were control mice and were first injected with PBS + CFA and then immunized with CII as mice in other groups. In this group, $7 / 8$ mice $(87 \%)$ developed severe clinical arthritis within $40 \mathrm{~d}$ of immunization with CII with the mean day of onset of arthritis being day 29 (Table I). Thus, it is clear that in mice $(n=20)$ preimmunized with a mixture of TCR V $\beta$ 3 and $\mathrm{V} \beta 10$ peptides (group A and group A1, Table I), none of the mice developed any clinical symptoms of arthritis after immunization and boosting with CII. These results demonstrated that susceptibility of BUB mice to the development of CIA can be abrogated by immunization with TCR V 33 and $\mathrm{V} \beta 10$ peptides before immunization with CII.

We also determined whether immunization with TCR V 33 and $\mathrm{V} \beta 10$ peptides after antigenic challenge could influence the disease outcome. We immunized five BUB mice with CII + CFA and $10 \mathrm{~d}$ later these mice were injected with TCR V 3

Table I. Immunization with TCR V $\beta$ Peptides Prevented the Induction of CIA

\begin{tabular}{lccc}
\hline \multicolumn{1}{c}{ Immunization protocol } & Incidence & $\begin{array}{c}\text { Mean day } \\
\text { of onset* }\end{array}$ & Severity of CIA \\
\hline TCR V $\beta 3$ \& $10+$ CFA $^{\S}$ & $0 / 20(0 \%)$ & 0 & 0 \\
CII + CFA 10 d later & & & \\
TCR V $\beta 14+$ CFA & $5 / 6(83 \%)$ & $30 \pm 2.5$ & $2,2,1.5,2,2$ \\
CII + CFA 10 d later & & & \\
PBS + CFA & $7 / 8(87 \%)$ & $29 \pm 1.7$ & $2,2,2,2,2.5,2,2$ \\
CII + CFA 10 d later & & & \\
\hline
\end{tabular}

* Day of onset was counted from the day of first immunization with CII. *The severity of arthritis on the day of onset in each of the affected mice in all groups was determined by evaluating fore and hind paws for swelling and redness. The severity of arthritis was scored on a subjective scale $(0-4)$ as previously described $(15,16)$. Mice in all groups were monitored four times a wk for clinical symptoms of arthritis. ${ }^{\S} \mathrm{A} 1 \mathrm{mg} / \mathrm{ml}$ mixture (500 $\mu \mathrm{g}$ of each peptide in PBS) of TCR V $\beta 3$ and V $\beta 10$ peptides (KGQGQKAKMRCIPEKGH and QTLDHNTMYWYKQDSKKLLKIM [single letter amino acid code], respectively), representing amino acid residues 13-29 of TCR V 33 and amino acid residues 25-46 of TCR V $\beta$ 10, was emulsified with equal volume of CFA (GIBCO BRL) and $100 \mu \mathrm{l}$ of this solution was injected intradermally in the tail of BUB mice. $10 \mathrm{~d}$ later, mice were immunized with chicken type-II collagen emulsified in CFA and 3 wk later were boosted with CII + IFA. $\| 1 \mathrm{mg} / \mathrm{ml}$ solution (in PBS) of murine TCR V $\beta 14$ peptide (ATGGTLQQLFYSITVGQV) representing amino acid residues 39-56 was emulsified with equal volume of CFA and $100 \mu \mathrm{l}$ was injected intradermally in the tail. These mice were then immunized with CII + CFA and treated exactly as above. "A mixture containing equal volumes of PBS and CFA was emulsified and $100 \mu \mathrm{l}$ was injected intradermally in the tails. These mice were then immunized with $\mathrm{CII}+\mathrm{CFA}$ and treated identically to mice in other groups. 
Table II. Protective Effects of Immunization of BUB Mice with TCR V $\beta$ Peptides after Antigenic Challenge with Chicken Type-II Collagen

\begin{tabular}{lccc}
\hline Immunization protocol* & Incidence & $\begin{array}{c}\text { Mean day } \\
\text { of onset }\end{array}$ & Severity of arthritis \\
\hline CII + CFA & & & \\
$\begin{array}{l}\text { 10 d later TCR V } 3 \\
\quad \text { V } \beta \text { 10 in CFA }\end{array}$ & $1 / 5(20 \%)$ & $32 \pm 1.7$ & 2.0 \\
CII + CFA & & & \\
PBS + CFA 10 d later & $4 / 4(100 \%)$ & $30 \pm 2.3$ & $2.5,1.0,2.0,2.0$
\end{tabular}

* Mice were immunized with a $100 \mu \mathrm{l}$ of a mixture of $250 \mu \mathrm{g} / \mathrm{ml}$ of each of the TCR V $\beta$ peptides emulsified with an equal volume of CFA. Mean day of onset and severity of arthritis, in each mouse on the day of onset, were determined as previously described (15).

and V $\beta 10$ peptides in CFA and then boosted with CII + IFA $3 \mathrm{wk}$ later. These mice were also monitored for $40 \mathrm{~d}$ for the development of clinical symptoms of arthritis. Table II shows the protective capacity of this treatment. A significant $(P<0.05)$ number of mice $(4 / 5,80 \%)$ in this group did not develop any symptoms of arthritis during the course of these studies. In contrast, in the control group (no TCR V $\beta$ peptide immunization after immunization with CII + CFA), $100 \%$ of the mice developed severe arthritis with the mean day of onset being day 30. Although the number of mice used in this experiment was small, these results suggest that protective immunity against CIA can be induced by TCR V $\beta$ peptide vaccination after primary challenge with the chicken type-II collagen.

Histological analysis of the joints. A characteristic of arthritic joints in mice with CIA is the synovial hyperplasia, pannus formation, exudation of cells into the joint space, and erosion of bone and cartilage. Histological examination of some of the hind paws $(n=4)$ from arthritis-protected mice revealed no signs of inflammatory processes (Fig. $1 B$ ). Immunization with a mixture of TCR V 33 and V $\beta 10$ peptides prevented not only the inflammatory cell influx, but also cartilage and bone destruction. In contrast, histological examination of arthritic joints from mice first treated with control TCR V $\beta 14$ peptide (group B) or mice from group $\mathrm{C}$ showed arthritic joints characterized principally by a highly fibrous and cellular pannus (Fig. $1 \mathrm{~A}$ ). Massive influx of inflammatory cells, synovial hyperplasia, and accumulation of abundant mono- and polymorphonuclear cells in the joint space was evident (Fig. $1 A$ ). Thus, the appearance of articular cartilage and synovium in the present study was identical to characteristics of arthritic joints, as previously described (16). In contrast, as can be seen in Fig. $1 A$, the synovial membrane in the joints of arthritis-protected mice was like normal synovium with no signs of synovial hyperplasia or other characteristics of inflammation. Thus, the absence of clinical arthritis in mice immunized with TCR V 33 and V $\beta$
Table III. TCR V及 10 Peptide Was More Effective in Preventing CIA Than TCR V 3 Peptide When Used Alone

\begin{tabular}{lccc}
\hline Immunization protocol & Incidence & $\begin{array}{c}\text { Mean day } \\
\text { of onset* }\end{array}$ & Severity of arthritis \\
\hline TCR V $\beta 3+$ CFA $\$$ & & & \\
CII + CFA 10 d later & $4 / 6(66 \%)$ & $33 \pm 2.7$ & $1.0,1.5,2.0,2.0$ \\
TCR V $\beta$ 10 + CFA & & & 1.0 \\
CII + CFA 10 d later & $1 / 7(14 \%)$ & $39 \pm 1.3$ & \\
\hline
\end{tabular}

*Day of onset of arthritis was counted from the day of immunization with CII. ${ }^{\ddagger}$ The severity of arthritis in each affected mouse on the day of onset was determined as described above. ${ }^{\S} \mathrm{A} 500 \mu \mathrm{g} / \mathrm{ml}$ solution of TCR V 3 peptide was emulsified with equal volume of CFA and $100 \mu l$ was injected intradermally in the tail. Mice were then treated for the induction of arthritis as described in Table I. ${ }^{\| A} 500 \mu \mathrm{g} / \mathrm{ml}$ solution of TCR V $\beta 10$ peptide was emulsified with equal volume of CFA and 100 $\mu l$ was injected intradermally in the tail. Mice were then treated for the induction of arthritis as described in Table I.

10 peptides (Table I) was not simply the result of a subclinical level of inflammation, but due to complete absence of inflammatory process in the synovium.

Protective effect of immunization with either TCR V 33 or $T C R V \beta 10$ peptide. We also studied whether preimmunization of BUB mice with either TCR V $\beta 3$ or TCR V $\beta 10$ peptide alone would also induce protective immunity against CIA. The results of an experiment where mice were immunized with only one TCR V $\beta$ peptide, $10 \mathrm{~d}$ before immunization with CII + CFA are shown in Table III. There was slightly delayed onset of arthritis in mice immunized with TCR V 3 peptide, but the incidence of arthritis was high. Four out of six mice $(66 \%$ incidence), preimmunized with TCR V 33 peptide before immunization with CII, developed clinical arthritis with mean day of onset being day 33 (Table III). On the other hand, out of seven mice immunized with TCR V $\beta 10$ peptide before immunization with CII, only one mouse developed clinical symptoms of arthritis around day 39 (14\% incidence) after immunization with CII (Table III). Because of the delayed onset of arthritis in this case, the observation period for this group of mice was extended for an additional $10 \mathrm{~d}$. Very mild, transitory arthritis affecting only the toes was also observed in another mouse on day 42. This mouse never developed full CIA as no erythema or swelling of the major joints was observed. These data suggest that immunization with TCR V $\beta 10$ peptide alone was sufficient to induce protective immunity against CIA as compared to immunization with TCR V 3 peptide.

Effect of immunization with TCR V $\beta$ peptides on serum antibody titers. Both the cell-mediated and humoral immune responses have been postulated to play a role in the pathogenesis of CIA (1-3). A consequence of immunization with CII is a rise in serum IgG reactive with $\mathrm{CII}$ and it is an important factor in establishing arthritis in mice. Therefore, we investigated

Figure 1. The prevention of histologic changes characteristic of CIA by immunization with a mixture of TCR V 33 and TCR V $\beta 10$ peptides. Arthritic and nonarthritic mice (Table I) were killed $40 \mathrm{~d}$ after primary immunization with chicken type-II collagen and their hind paws were formalin fixed and processed as previously described (16). Tissue sections were examined under microscope and the results are depicted with a representative sample from $(A)$ mice immunized with saline + CFA and $(B)$ mice immunized with a mixture of TCR V 33 and V $\beta 10$ peptides. In $A$, a fibrous and highly cellular pannus $(P)$ was clearly visible. The pannus had extended into the sites of bone erosion (arrow). In comparison, in $B$, the synovial membrane was basically identical to normal synovium $(S)$ with no signs of synovial hyperplasia or other characteristics of inflammation. 

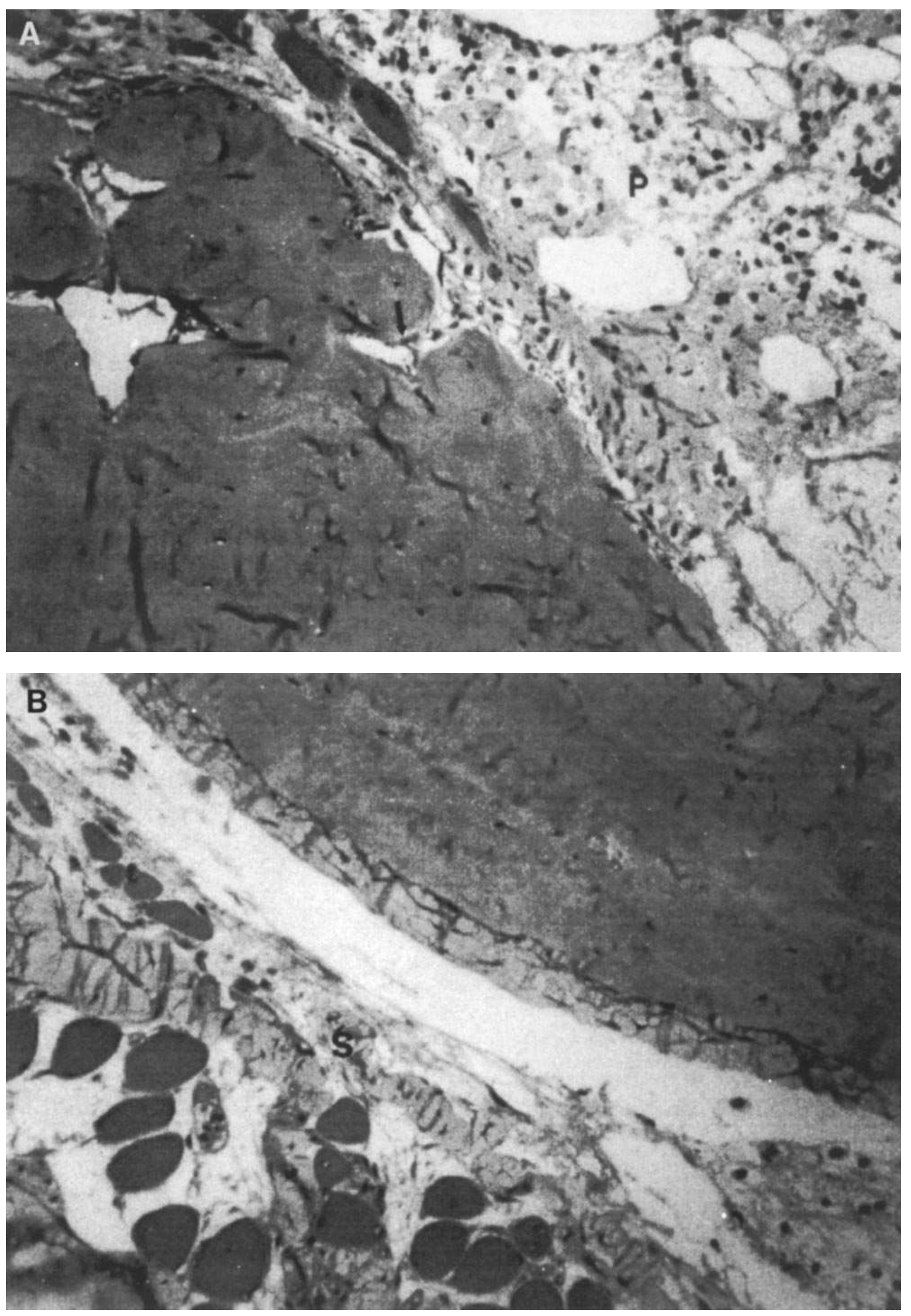
whether immunization of BUB mice with TCR V $\beta$ peptide fragments affected the production of antibodies reactive with the immunizing antigen and the autoantigen. Collagen-specific and Ig isotype-specific ELISAs were used to evaluate the levels of anti-chicken type-II collagen- and anti-mouse type-II collagen-specific antibodies and the $\mathrm{IgG}$ isotypes, respectively, present in the serum of arthritic and arthritis protected mice. The results of representative experiments are shown in Figs. 2 and 3. Irrespective of treatments before immunization with CII, all of the mice immunized with CII + CFA for the induction of arthritis produced comparable levels of anti-chicken type-II collagen antibodies in comparison with unimmunized mice (Fig. 2). When serum samples were analyzed for the presence of antibodies reactive with the mouse type-II collagen in arthritic and arthritis-protected mice, using specific ELISAs, it was found that the levels of antibodies reactive with mouse type-II collagen were lower $(P<0.05)$ in arthritis-protected mice in comparison to mice with arthritis (Fig. 2). Therefore, treatment with TCR peptides did not alter the production of antibodies specific for the immunizing antigen. However, influence of immunization with TCR V $\beta$ peptides was apparent on the level of Ig subclasses in serum of arthritis-protected mice when compared to arthritic mice (Fig. 3). Mice in both groups produced similar amounts of $\operatorname{IgG} 2 \mathrm{~b}$ antibodies while the level of $\operatorname{IgG} 2 \mathrm{a}$ antibodies, reactive with type-II collagen, was lower in arthritis-protected mice (Fig. 3). This suggests that in arthritis-protected mice, production of IgG2a subclass of antibodies was affected as a result of immunization with TCR V $\beta$ peptides. Our data thus indicate that mice treated with TCR V 3 and V $\beta 10$ peptides (arthritis protected) produced antibodies reactive with the autoantigen, but there was

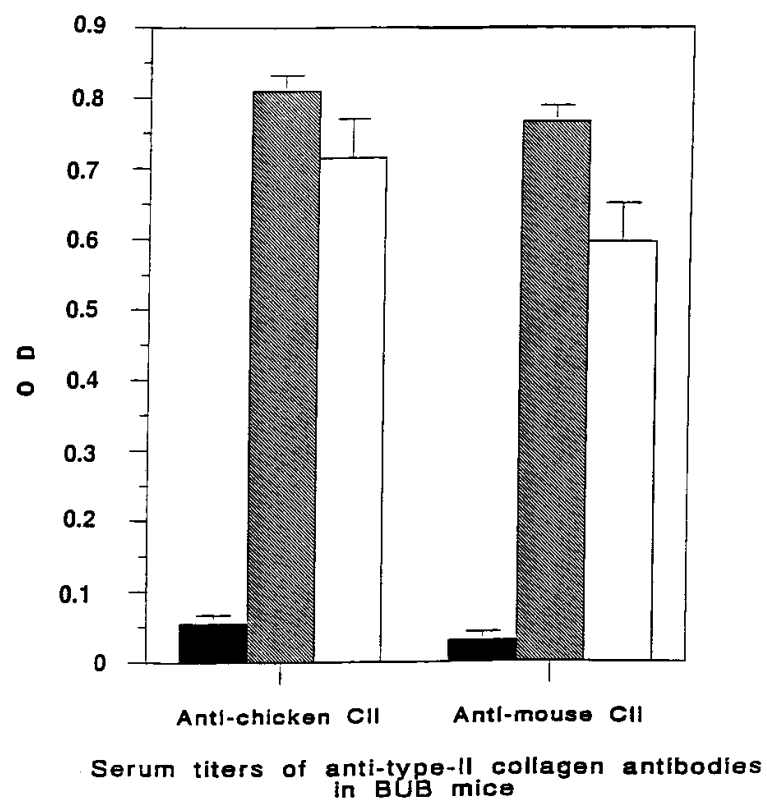

Figure 2. Serum titers of anti-type-II collagen antibodies in arthritic and arthritis-protected mice. Serum titers were determined by an ELISA method. Mice in both groups developed high titers of antichicken type-II collagen antibodies. However, titers of antibodies crossreactive with the mouse type-II collagen were lower in arthritisprotected mice in comparison to arthritic mice. $\mathbf{\square}$, unimmunized; arthritic; $\square$, arthritis-protected. a reduction in the level of this class of antibodies in comparison to the level in arthritic mice. Although present, these antitype-II collagen antibodies by themselves were insufficient to induce inflammatory responses in the joints of mice immunized with TCR V 33 and V $\beta 10$ peptides. Our data thus suggest that in mice immunized with TCR V $\beta$ peptides, there was a potential interference with the maturation of humoral immune response against CII. Interference or blockage in the development of humoral immune response against the autoantigen could account for the protective immunity against CIA in BUB mice immunized with TCR V $\beta$ peptides.

We also adapted an ELISA method to determine whether animals immunized with TCR V $\beta$ peptide fragments produced antibodies specific for the immunizing peptide fragments. The results of a representative analysis are shown in Fig. 4. All of the BUB mice immunized with TCR V $\beta 3$ and V $\beta 10$ peptides also produced antibodies specific for TCR V $\beta 10$ and V 33 peptides (Fig. 4, $A$ and $B$ ). Anti-V 33 or anti-V $\beta 10$ peptide antibodies were not detected in the serum of unimmunized mice (open circles, Fig. 4, $A$ and $B$ ) or in mice immunized with $\mathrm{CII}+\mathrm{CFA}$ for the induction of CIA (results not shown). These results thus indicate that antibodies reactive with TCR $\mathrm{V} \beta$ peptides were produced in response to immunization with these peptides.

Influence of immunization with TCR V $\beta$ peptides on TCR repertoire. We also determined the effect of immunization with TCR V 33 plus V $\beta 10$ peptides and TCR V $\beta 14$ peptide on the repertoire of $\mathrm{T}$ cells expressing $\mathrm{V} \beta 2,4,6,13,14$, and $17^{\mathrm{a}}$ genes in the LN using the commercially available FITClabeled antibodies. Using the LN cells stained with the anti-

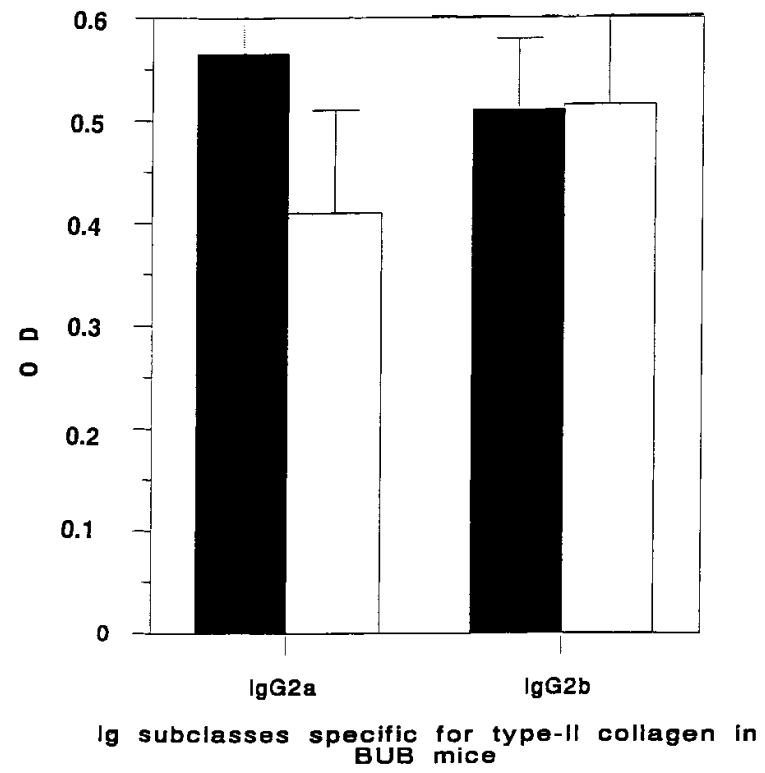

Figure 3. Serum titers of Ig subclasses reactive with chicken type-II collagen in arthritic and arthritis-protected mice. Serum titers were determined by an ELISA method using the mouse IgG isotyping kit (PharMingen) according to the instructions provided with the kit. Sera were obtained at the end of studies ( $40 \mathrm{~d}$ after immunization with CII for the induction of arthritis). Samples were run in quadruplicate from each mouse. Error bars indicate standard error of mean. $\mathbf{\square}$, arthritic; $\square$, arthritis-protected. 


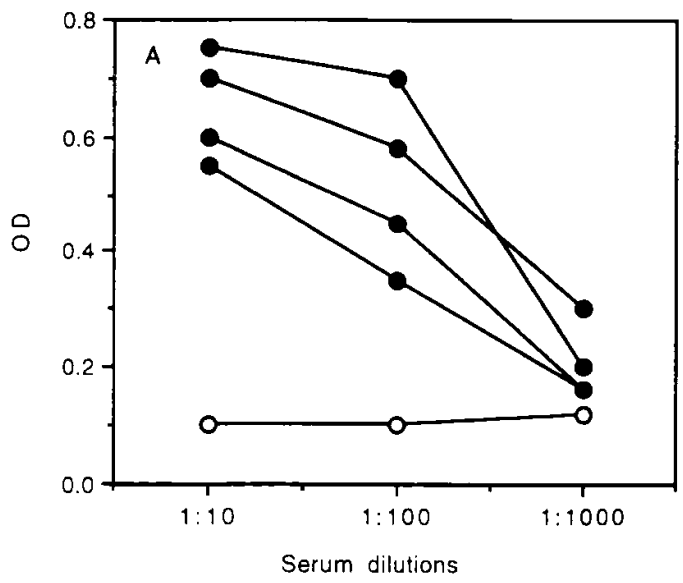

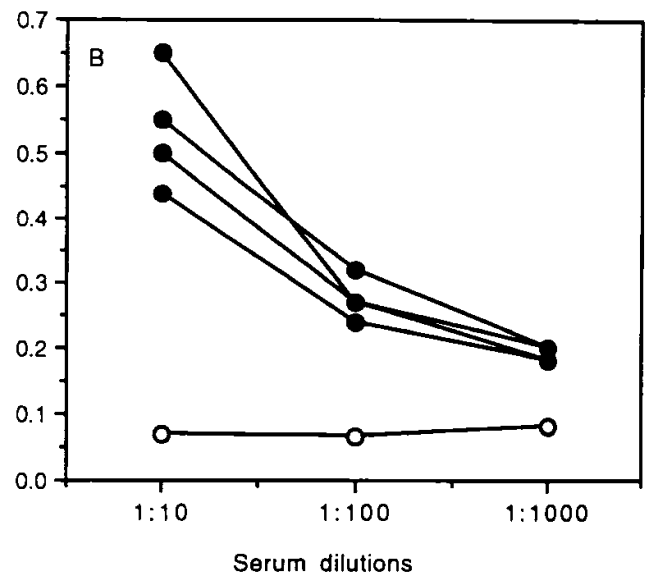

Figure 4. Serum titers of $(A)$ anti-V $\beta 10$ peptide and $(B)$ anti-V $\beta 3$ peptide antibodies in arthritis-protected mice ( and in control, unimmunized mice $(\bigcirc)$. Serum samples from arthritisprotected mice and control mice were analyzed for the presence of mouse anti-V $\beta 10(A)$ and mouse anti-V $33(B)$ antibodies by modifying an ELISA method as described in Methods. All of the arthritis-protected mice analyzed had high titers of anti-TCR V $\beta$ peptide antibodies in comparison to unimmunized mice. bodies specific for the murine TCR V $\beta 2,4,6,13,14$, and $17^{\mathrm{a}}$ and two-color FACS ${ }^{\circledR}$ analysis with anti-CD3 mAb, we failed to detect any significant changes in the percentages of $\mathrm{T}$ cells bearing these markers in the arthritic and arthritis-protected mice (Table IV $A$ ). These results provide indirect evidence that immunization with TCR V $\beta 3$ and V $\beta 10$ peptides did not grossly alter the $\mathrm{T}$ cell repertoire in the $\mathrm{LN}$ of these mice. These results were not unexpected as mice were not immunized against these receptors and $T$ cells bearing these recep-

Table IV A. T Cell Receptor V $\beta$ Gene Expression in LN of BUB Mice

\begin{tabular}{ccc}
\hline TCR V $\beta$ & Arthritic mice* & $\begin{array}{c}\text { Arthritis-protected } \\
\text { mice }\end{array}$ \\
\hline & $\%$ & $\%$ \\
2 & 7.10 & 8.40 \\
4 & 7.00 & 7.60 \\
6 & 6.00 & 7.00 \\
13 & 0.50 & 0.60 \\
14 & 7.20 & 9.20 \\
$17 *$ & 6.70 & 8.10 \\
\hline
\end{tabular}

Table IV B. Expression of $V \beta 3$ and $V \beta 10 \mathrm{mRNA}$ in LN Cells of BUB Mice as Determined by a Semiquantitative PCR Method M $^{\S}$

\begin{tabular}{rrr}
\hline 3 & 17.7 & 17.1 \\
10 & 7.94 & 0.1 \\
\hline
\end{tabular}

*These mice were immunized with TCR V $\beta 14$ peptide before immunization with CII for the induction of CIA. ${ }^{*}$ Mice in this group were immunized with TCR V $\beta 3+\mathrm{V} \beta 10$ peptides before immunization with CII for the induction of CIA. ${ }^{8}$ Data for the expression of $\mathrm{V} \beta 3$ and $\mathrm{V} \beta$ 10 are expressed in terms of percentage radiographic intensity of bands relative to the intensity of the C $\beta$ DNA band, which was taken as $100 \%$. Data for other $\mathrm{V} \beta$ genes were obtained by two-color FACS ${ }^{\circledR}$ analysis. tors have not been shown to be important in the pathogenesis of arthritis in this model.

Since antibodies reactive with TCR V 33 and V $\beta 10$ in BUB mice (TCR V $\beta^{a}$ ) are not available, we determined the expression of TCR V $\beta 3$ and $V \beta 10$ genes in the same mice by a semiquantitative PCR method (Table IV $B$ ). These results demonstrate that expression of TCR V $\beta 3$ was very similar in arthritic and arthritis protected mice in all the samples $(n=2)$ analyzed (Table IV $B$ ). This was interesting as arthritis-protected mice (immunized with TCR V $\beta 3$ and V $\beta 10$ peptides before immunization with CII for the induction of arthritis) had high titers of anti-V 33 peptide antibodies (Fig. 4 B), but there was no difference in the level of expression in comparison to arthritic mice (negative for anti-V 3 peptide antibodies). This would suggest that these antibodies were not reactive with the native TCR and, as a consequence, V $\beta$ 3-expressing cells were not deleted. However, and significantly, expression of TCR V $\beta 10$ was drastically altered in arthritis-protected mice in comparison to arthritic mice (Table IV $B$ and Fig. 5). Expression of TCR V $\beta 10$ was 80 -fold higher in arthritic mice in comparison to arthritis-protected mice. The weak radiographic band detected in arthritis-protected mice had radiographic intensity of only $0.1 \%$ relative to the TCR C $\beta$ band which represented total $\mathrm{T}$ cell population. To determine if there was a systemic deletion of TCR V $\beta$ 10-expressing T cells in arthritis-protected mice, or the absence was confined to draining LNs, we determined the relative expression of TCR $\mathrm{V} \beta 3$ and V $\beta 10$ in spleen cells from arthritic and arthritis-protected mice (Fig. 5 B). T cells expressing TCR V 33 and V $\beta 10$ were present in the spleens of both arthritic and arthritis-protected mice, but the expression of TCR V $\beta 10$ was barely detectable in arthritis-protected mice (Fig. $5 B$ and results not shown). This strengthens our conclusion that V $\beta$ 10-expressing $T$ cells were either deleted or receptor down-regulated in arthritis-protected mice. More significantly, our results imply that, despite the presence of $\mathrm{V} \beta 3$ and $\mathrm{V} \beta$ 10-expressing $\mathrm{T}$ cells in arthritic joints of BUB mice (12), only the TCR V $\beta$ 10-expressing $\mathrm{T}$ cells appear to be pathogenic as the difference in their level of expression in the LN cells in arthritic and arthritis-protected mice correlates with the presence or absence 

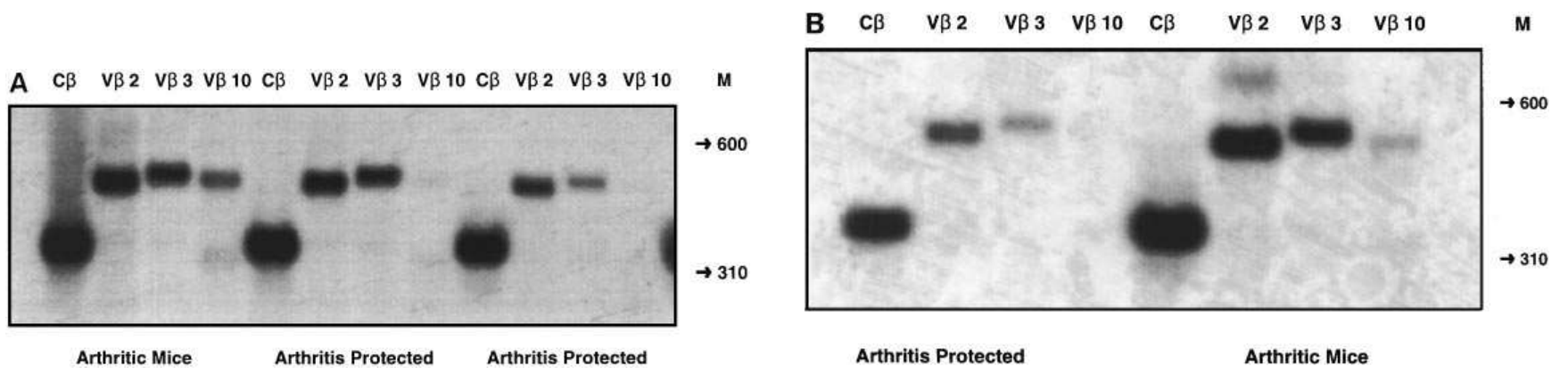

Figure 5. Analysis of TCR V $\beta$ chain gene expression in lymph node and spleen cells of arthritis-protected and arthritic BUB mice. Arthritisprotected and arthritic BUB mice from each group (Table I) were killed at the termination of the experiment, and draining lymph node cells and spleen cells were prepared by the standard methods. Preparation of total cellular RNA, cDNA synthesis, and PCR-assisted amplification of murine TCR V $\beta$ transcripts was performed essentially as described in Methods. The autoradiogram in $A$ shows the presence of TCR V $\beta 10$ transcripts in lymph node cells of arthritic mice but not in the lymph node cells of arthritis-protected mice. However, as shown in $B$, in the spleen cells of arthritis-protected mice, expression of both TCR V 33 and TCR V $\beta 10$ genes was very much reduced as compared to spleen cells of arthritic mice. Densitometric scanning analysis indicated that the radiographic intensity of the hybridizing band in the V $\beta 10$ lane in arthritis-protected mouse sample was only $0.1 \%$ of the C $\beta$ DNA band, which was taken as $100 \%$. $M$, DNA molecular size standard (Phi- $\times 174$ DNA digested with HaeIII).

of CIA in BUB mice immunized with CII. These results also indicate that $\mathrm{V} \beta$ 3-expressing $\mathrm{T}$ cells by themselves were insufficient to cause an inflammatory response.

Passive transfer of protective effects with serum from arthritis-protected mice. We carried out an adoptive transfer experiment to determine whether protective immunity against CIA in BUB mice immunized with TCR V 33 and $V \beta 10$ peptides is due to the elicitation of anti-V $\beta 3$ and anti-V $\beta 10$ antibodies. Serum obtained from arthritis-protected mice, arthritic mice, or normal mice were adoptively transferred into different groups of naive BUB mice, which were then immunized with CII in CFA. All of the mice treated this way were individually examined for the development of clinical symptoms of arthritis up to day 60 after primary immunization with CII in CFA. As shown in Table $\mathrm{V}$, infusion of multiple doses of serum from arthritis-protected mice significantly $(P<0.005)$ influenced the onset of CIA in recipient BUB mice with the mean day of onset being day 48. In addition, mice injected with serum from arthritis-protected mice that developed arthritis did so at a slower rate. Although the onset of arthritis was delayed in mice injected with serum from arthritis-protected mice, once induced, there was no significant difference $(P>0.05)$ in the severity of the disease on the day of onset when compared to mice injected with serum from normal BUB mice (Table V). Mice injected with serum from arthritic mice developed arthritis earlier than other groups and the severity of arthritis on the day of onset in this group was significantly $(P<0.005)$ higher in comparison to other groups (Table V). We thus conclude that multiple infusions of serum from arthritis-protected mice significantly delayed the induction of disease in treated BUB mice, but it had no effect on the severity of arthritis in mice that developed CIA when compared to mice that received serum from normal mice. We also analyzed the TCR V $\beta$ expression in LN cells of BUB mice after three injections of serum from arthritis-protected mice. Preliminary results indicate that T cells expressing TCR V 33 were apparently not affected by such treatment, but TCR V $\beta$ 10-expressing T cells were virtually absent (results not shown). However, later analysis of TCR V $\beta$ expression in some of the mice at the end of experiment showed the presence of $\mathrm{T}$ cells expressing V $\beta 10$ (results not shown). Our data further demonstrate that serum from arthritis-protected mice could modulate the repertoire of $\mathrm{T}$ cells expressing TCR V $\beta$ 10. Taken together, our results indicate that immunization with TCR V $\beta 3$ and V $\beta 10$ peptides interfered with the development of cellular and humoral immune responses against $\mathrm{CII}$ by deleting pathogenic $\mathrm{T}$ cells and that this deletion was most likely mediated via antibodies reactive with the self-TCR.

\section{Discussion}

Our previous results suggested that TCR V $\beta 3$ - and V $\beta 10$ expressing $\mathrm{T}$ cells may be important in the pathogenesis of type-II collagen-induced arthritis in susceptible BUB mice (12). Results presented here provide additional evidence supporting a role for specific TCR V $\beta$-bearing $T$ cells in the induction and progression of arthritis in this animal model. More importantly, we found that immunization of BUB mice with a mixture of TCR V $\beta$ 3- and $\mathrm{V} \beta$ 10-region peptide fragments induced protective immunity against CIA (Table I). The ex-

Table V. Incidence and Severity of Arthritis in BUB Mice Injected with Serum from Arthritis-protected, Arthritic, and Normal BUB Mice

\begin{tabular}{llllr}
\hline $\begin{array}{c}\text { Number } \\
\text { of mice }\end{array}$ & \multicolumn{1}{c}{ Serum from } & Incidence & $\begin{array}{c}\text { Mean day } \\
\text { of onset* }\end{array}$ & $\begin{array}{c}\text { Mean severity } \\
\text { of arthritis }\end{array}$ \\
\hline 8 & Arthritis-protected mice & $5 / 8(62 \%)$ & $48 \pm 3.5$ & $1.45 \pm 0.6$ \\
4 & Arthritic mice & $4 / 4(100 \%)$ & $24 \pm 1.7$ & $3.12 \pm 0.8$ \\
4 & Normal BUB mice & $3 / 4(75 \%)$ & $29 \pm 1.5$ & $1.5 \pm 0.5$ \\
\hline
\end{tabular}

*Day of onset was the day when clinical symptoms of arthritis were first documented. In mice injected with serum from arthritis-protected mice, the onset of arthritis was significantly delayed $(P<0.005)$ in comparison to the other two groups. ${ }^{\ddagger}$ Severity of arthritis for each affected mouse was determined as above. In all groups of arthritic mice, hind paws were usually affected more in comparison to front paws. Severity of arthritis was significantly $(P<0.005)$ higher on the day of onset in mice injected with serum from arthritic mice. 
tent of protection was analyzed by histologic evaluation of joints from arthritic and arthritis-protected mice. The absence of inflammatory process in the joints of arthritis-protected mice (Fig. $1 B$ ) indicated that immunization with TCR V $\beta-$ region peptides blocked the joint infiltration by inflammatory cells and subsequent joint destruction. Our results also demonstrate that immunization with TCR V $\beta$ peptides, after the antigenic challenge with CII, can also significantly influence the incidence of CIA in BUB mice (Table II). Immunization of BUB mice with either TCR V $\beta$ 3- or TCR V $\beta$ 10-region peptides alone, before immunization with CII, indicated that preimmunization with TCR V $\beta$ 10-region peptide was more effective in inducing protective immunity against CIA (Table II). Here also, the incidence and severity of arthritis was significantly reduced in comparison to mice immunized with TCR V $\beta 3$ peptides. This clearly implicates TCR V $\beta$ 10-expressing $T$ cells in the induction of CIA in BUB mice. This view was further supported by the analysis of TCR V $\beta$ chain gene expression in LN cells of arthritic and arthritis-protected mice.

Analysis of TCR V $\beta$ chain gene expression, by using PCRassisted amplification of TCR V $\beta$ transcripts, in LN cells revealed that in arthritis-protected BUB mice (immunized with the mixture of TCR V $\beta 3$ - and V $\beta$ 10-region peptides) TCR $\mathrm{V} \beta$ 10-expressing $\mathrm{T}$ cells were virtually absent in the draining lymph nodes and barely detectable in the spleens (Fig. 5, $A$ and $B$ ). Therefore, protective immunity against CIA was most likely due to the clonal elimination of TCR V $\beta$ 10-expressing T cells. The presence of TCR V $\beta 3$-expressing T cells in arthritis-protected mice suggests that, in the absence of TCR V $\beta 10$ expressing T cells, TCR V $\beta$ 3-expressing T cells by themselves were insufficient to cause an inflammatory response. However, the pathogenic importance of either $\mathrm{V} \beta 3$ - or V $\beta$ 10-expressing $T$ cells awaits confirmation by adoptive transfer studies.

TCR V $\beta$ peptide vaccination was first reported to be successful in preventing the development of EAE in rats. In this model, disease prevention was thought to be due to the activation of anti-TCR regulatory $\mathrm{T}$ cells $(9,10)$. More recently, TCR peptide vaccine was also reported to be effective in preventing an alloresponse (18). In this study, TCR peptide was contemplated to function as an antagonist, competing with the native TCR for recognition of the $\mathrm{L}^{\mathrm{d}}$ present on stimulatory cells. Another study, using the adjuvant arthritis model in Lewis rats, suggests that $\mathrm{T}$ cells can process and present their own TCR proteins to anti-TCR peptide-specific, MHC class II-restricted T cells. These T cells were generated in response to immunization with TCR V $\beta$-region peptides and these $\mathrm{T}$ cells then probably act as regulatory $\mathrm{T}$ cells (19). Therefore, prevention of undesirable immune response with TCR V $\beta$ peptide fragments may result either in clonal deletion, recognition competition, or activation of regulatory $\mathrm{T}$ cells.

The mechanism(s) responsible for the clonal deletion of TCR V $\beta$ 10-expressing T cells is not known. All the animals immunized with TCR V 3 and V $\beta 10$ peptides developed high titers of antibodies specific for the $\mathrm{V} \beta$ peptides. Presence of these antibodies may eliminate the corresponding V $\beta$-bearing $\mathrm{T}$ cells by complement-mediated lysis or antibody-dependent cellular cytotoxicity. This interpretation was further supported by our observation that adoptive transfer of serum from arthritis-protected mice, but not from normal or arthritic mice, can delete V $\beta$ 10-expressing $\mathrm{T}$ cells and significantly delay the onset of arthritis in recipient mice. Despite the fact that both anti-V $\beta 3$ and anti- V $\beta 10$ peptide antibodies were detected in mice immunized with a mixture of TCR V 33 and V $\beta 10$ peptides, only TCR V $\beta$ 10-expressing T cells were eliminated. One possibility (yet to be determined) is that the anti-V $\beta 3$ peptide antibodies elicited were unable to react with the intact V $\beta 3$ TCR. We were unable to detect proliferative responses against TCR V $\beta 3$ and V $\beta 10$ peptides $50 \mathrm{~d}$ after immunization (results not shown). It has been reported that anti-T cell receptor proliferative responses can be demonstrated in rats immunized with TCR peptides and that only certain regions of the TCR peptides are immunogenic (19). Thus, it is possible that, while $\mathrm{V} \beta 10$ peptides were able to induce an antibody response, they were not successful in eliciting an effective cellmediated immune response. The protection rendered by immune sera from arthritis-protected mice (Table V) strongly implicate the development of an effective humoral immune response against the pathogenic $\mathrm{T}$ cells in the induction of protective immunity against CIA. Although mice injected with serum from arthritis-protected mice eventually developed CIA, this could be due to "clearing" or dilution of protective antibodies. This indicates that the prevention of disease requires the continuous presence of anti-V $\beta$ antibody (a situation that can occur in mice immunized with the TCR V $\beta$ peptides). In the absence of continuous antibody production, new V $\beta 10$ bearing $\mathrm{T}$ cells may be able to regenerate from the precursor pool. The presence of $\mathrm{V} \beta 10 \mathrm{mRNA}$ in LN cells in some of the mice (results not shown) at the end of this study argues in favor of this hypothesis.

Type-II collagen-induced arthritis in mice is a cell-mediated autoimmune inflammatory response. However, antitype-II collagen antibodies have been reported to play an important role in the pathogenesis of arthritis (3). Initial lesions in CIA are probably related to the production of IgG autoantibodies reactive to the antigenic determinants of the CII. These antibodies may bind to articular cartilage and activate the complement cascade (20). In our experiments, all of the BUB mice immunized with TCR V $\beta$-region peptides developed high titers of anti-type-II collagen antibodies. But titers of antibodies reactive with the mouse type-II collagen were lower in arthritis-protected mice. Despite the presence of anti-type-II collagen antibodies cross-reactive with the immunizing antigen and autoantigen, these mice remained disease free during the course of these studies. Thus, the absence of CIA in these mice could be associated with reduced humoral responses to the autoantigen mouse type-II collagen, in combination with the deletion or downregulation of V $\beta$ 10-expressing T cells. Another possibility remains that the "qualities" of anti-type-II collagen antibodies produced in the TCR V $\beta$ peptide-immunized mice may be different from anti-type-II collagen antibodies in arthritic mice. Differences in the affinities of the antibodies produced may also alter the course of the disease.

In conclusion, results reported here indicate a role for antiTCR peptide-specific responses in the induction of protective immunity against CIA. The exact mechanism(s) by which these anti-TCR peptide-specific responses interferes with the development of CIA remains to be determined, but appears to be a consequence of the development of antibodies reactive with the self-TCR. This is interesting because, as in other cases, immunization with TCR peptides has been reported to induce the development of antiidiotypic regulatory cells $(9,10)$. Elicitation of antibodies reactive with the self could be a characteristic of the strain used (BUB/BnJ), the TCR V $\beta$ peptides used for the immunization, or a combination of both. This remains 
to be investigated. Nevertheless, our data demonstrate that immunization with TCR V $\beta$-specific peptides or passive administration of antibodies specific for pathogenic V $\beta$-bearing $\mathrm{T}$ cells may have clinical applications in treating human autoimmune diseases characterized by common TCR gene usage.

\section{Acknowledgments}

This work was supported, in part, by grants AR-40672 (R29, FIRST Award), AR-20618 (NEOMAC), and AR-38018 from the National Institutes of Health.

\section{References}

1. Haqqi, T.M., and C.S. David. 1990. T cell receptor V $\beta$ gene repertoire in mice: Possible role in resistance and susceptibility to type-II collagen induced arthritis. J. Autoimmun. 3:113-121.

2. Holmdahl, R., V. Malmstrom, and E. Vuorio. 1993. Autoimmune recognition of cartilage collagens. Ann. Med. 25:251-264.

3. Holmdahl, R., M. Andersson, T.J. Goldschmidt, K. Gustaffson, L. Jansson, and J.A. Mo. 1990. Type-II collagen autoimmunity in animals and provocations leading to arthritis. Immunol. Rev. 118:193-232.

4. Myers, L.K., J.M. Stuart, and A.H. Kang. 1989. A CD4 cell is capable of transforming suppression of collagen induced arthritis. J. Immunol. 143:39763980 .

5. Haqqi, T.M., G.D. Anderson, S. Banerjee, and C.S. David. 1992. Restricted heterogeneity in $\mathrm{T}$ cell antigen receptor $\mathrm{V} \beta$ gene usage in the lymph nodes and arthritic joints of mice. Proc. Natl. Acad. Sci. USA. 89:1253-1255.

6. Osman, G.E., M. Toda, O. Kanigawa, and L.E. Hood. 1993. Characterization of the $\mathrm{T}$ cell receptor repertoire causing collagen arthritis in mice. $J$. Exp. Med. 177:387-395.

7. Acha-Orbea, H., D.J. Mitchell, L. Timmermann, D. Wraith, G.S. Tausch, M.K. Waldor, S.S. Zamvil, H.O. McDevitt, and L. Steinman. 1988. Limited heterogeneity of $\mathrm{T}$ cell receptors from lymphocytes mediating autoimmune encephalomyelitis allows specific immune intervention. Cell. 54:263-273.

8. Urban, J.L., V. Kumar, D.H. Kono, C. Gomez, S.J. Horvath, J. Clayton,
D.G. Ando, E.E. Sercarz, and L. Hood. 1988. Restricted use of T cell receptor $\mathrm{V}$ genes in murine autoimmune encephalomyelitis raises possibilities for antibody therapy. Cell. 54:577-592.

9. Vandenbark, A.A., G.A. Hashim, and H. Offner. 1989. Immunization with a synthetic $\mathrm{T}$ cell receptor $\mathrm{V}$ region peptide protects against experimental autoimmune encephalomyelitis. Nature (Lond.). 341:541-544.

10. Offner, H., G.A. Hashim, and A.A. Vandenbark. 1991. T cell receptor peptide therapy triggers autoregulation of experimental encephalomyelitis. Science (Wash. DC). 251:430-432.

11. Ortman, R.A., D. Holderbaum, X.-M. Qu, S. Banerjee, and T.M. Haqqi. 1994. BUB/BnJ $\left(\mathrm{H}-2^{\mathrm{q}}\right)$ is a T cell receptor deletion mutant strain (TCR V $\beta^{\mathrm{a}}$, $\mathrm{KJ}-16^{-}$) that is susceptible to collagen induced arthritis. J. Immunol. 152:41754182.

12. Haqqi, T.M., X.-M. Qu, M.S. Sy, and S. Banerjee. 1995. Restricted expression of $\mathrm{T}$ cell receptor $\mathrm{V} \beta$ and lymphokine genes in arthritic joints of a TCR V $\beta^{\text {a }}\left(\mathrm{H}-2^{\mathrm{q}}\right)$ mouse strain-BUB/BnJ-with collagen induced arthritis. J. Autoimmun. 20:163-170.

13. Margalit, H., J.L. Spouge, J.L. Cornett, K.P. Cease, C. Delisi, and J.A. Berzofsky. 1987. Prediction of immunodominant helper T cell antigenic sites from the primary sequence. J. Immunol. 138:2213-2229.

14. Rothbard, J.B., and W.R. Taylor. 1988. A sequence pattern common to T cell epitopes. EMBO. (Eur. Mol. Bio. Organ.) J. 7:93-102.

15. Banerjee, S., T.M. Haqqi, H.S. Luthra, J.M. Stuart, and C.S. David. 1988. Possible role of $\mathrm{V} \beta \mathrm{T}$ cell receptor genes in susceptibility to collageninduced arthritis in mice. J. Exp. Med. 167:832-839.

16. Durie, F.H., R.A. Fava, T.M. Foy, A. Aruffo, J.A. Ledbetter, and R.J. Noelle. 1993. Prevention of collagen induced arthritis with an antibody to gp39, the ligand for CD 40. Science (Wash. DC). 261:1328-1330.

17. Matsuoka, N., N. Bernard, E.S. Concepcion, P.N. Graves, A. Ben-Nun, and T. F. Davies. 1993. T-cell receptor V region $\beta$-chain gene expression in the autoimmune thyroiditis of non-obese diabetic mice. J. Immunol. 151:16911701 .

18. Goss, J.A., M.A. Alexander-Miller, J. Gorka, M.W. Flye, J.M. Conolly, and T.H. Hansen. 1993. Specific prolongation of allograft survival by a T cell receptor derived peptide. Proc. Natl. Acad. Sci. USA. 90:9872-9876.

19. Broeren, P.M., M.A. Lucassen, M.J.B. van Stipdonk, R. van der Zee, C.J.P. Boog, J.G. Kusters, and W. van Eden. 1994. CDR1 T-cell receptor $\beta$-chain peptide induces major histocompatibility complex class Iirestricted T-T cell interactions. Proc. Natl. Acad. Sci. USA. 91:5997-6001.

20. Stuart, J.M., W.C. Watson, and A.H. Kang. 1988. Collagen autoimmunity and arthritis. FASEB (Fed. Am. Soc. Exp. Biol.) J. 2:2950-2956. 